\title{
An evaluation of the information content of local authority websites in the UK using citizen-based scenarios
}

\author{
Wendy Olphert, Leela Damodaran
}

\begin{abstract}
The UK Government is pursuing ambitious targets for the delivery of egovernment at the local level. As part of the implementation of local egovernment, all of the 468 local authorities in the UK now have a website. Surveys show significant advances in the delivery of online local government services, but despite this the level of usage of e-government by citizens in the UK is low compared to other countries at a similar level of e-maturity. One reason hypothesised for this is that the websites do not meet citizens' information needs and consequently fail to engage them. A pilot study was undertaken to explore the use of real life scenario-based queries as a method for evaluating information provision on local authority websites. The findings suggest that even those websites that perform highly in terms of accessibility, transactional capability and ease of use will not necessarily meet citizens' information needs. The authors conclude that a citizen-centred approach to developing e-government systems, including the identification of information needs, could generate the 'user pull' needed to stimulate uptake and achieve the intended benefits.
\end{abstract}

\section{Introduction}

The consultancy organisation Accenture has carried out regular annual surveys of e-government services across the globe. These surveys have shown that the UK is regarded as being at the 'mature delivery' stage, and indeed Accenture suggest that most of the 22 counties surveyed have approached the limit in terms of the percentage of their services that they could put online (Accenture, 2005). Yet the

\section{Authors}

Wendy Olphert is a Senior Research Fellow and member of the Information, Technology \& Society Research Group in the Department of Information Science, Loughborough University.

Leela Damodaran is Professor of Change Management and Participative Design, and Head of the Information, Technology and Society Research Group in the Department of Information Science, Loughborough University.

Email: c.w.olphert@,lboro.ac.uk 
surveys also show that the UK's performance falls below that of other countries. In terms of the overall assessment of e-government maturity, the UK has been slipping - from 6th place in 2003 (Accenture, 2003) to 10th place in 2005 (Accenture, 2005). When assessed on the criterion of customer service maturity, i.e. the extent to which users can conduct a particular service with government, it was ranked 16th out of $22^{1}$. This situation suggests that there is considerable room for improvement in the UK in terms of the delivery of public services online, and this may account for the fact that levels of uptake of e-government in the UK are lower than other countries at a similar level of maturity. Accenture's figures from 2004 showed that only around $20 \%$ of UK citizens had used online government services to obtain information and only $3 \%$ had used public authority websites to submit information by completing forms online (Accenture, 2004). These figures can be contrasted with other countries that are implementing and promoting egovernment. For example, in Australia, nearly four in 10 Australian adults - and more than half of all adults who use the Internet - had contacted the Australian government via the Internet in the past 12 months (Australian Government Information Management Office, 2005), and in Norway using e-government sites to find information and to send in completed forms had been undertaken by $56 \%$ and $20 \%$ of the population respectively (Ottens, 2005).

This low level of uptake is a matter of concern for the UK government, which has invested heavily in e-government as a central part of its agenda to reform and modernise all public services. The objectives and priorities for e-government at the local level were set out in a document issued by the ODPM (Office of the Deputy Prime Minister), entitled "Defining e-government priority services and transformation outcomes in 2005 for local authorities in England (ODPM, 2004). The UK Government expects the transformation to e-government to yield improvements in information sharing between services and agencies, improved speed and efficiency of the processes that underpin services, and greater variety, choice and convenience of access for customers. However, a further aim is that online service delivery will lead to wider citizen participation and reduced social exclusion. To achieve these ambitious aims, e-government must not only deliver effective services online, but must offer advantages that will motivate citizens (especially those who are less likely to engage with government) to use them. Accenture emphasise that it is the provision of value-added services to the citizen which will provide the much needed impetus for e-government development (Accenture, 2006).

\section{E-government at the local level}

The primary delivery method for e-government is the Internet, and in the UK $80 \%$ of government transactions take place with local rather than central government. Therefore a fundamental requirement for implementing e-government at the local level was for each local authority in the UK to develop its own website, and this was achieved in line with Government targets by the end of 2005. All of the 468

\footnotetext{
${ }^{1}$ The example given is that a country that merely published information on finding taxes would score worse in that service than a country that allowed a citizen to actually file the taxes and receive verification that the transaction had gone through.
} 
local authorities in England and Wales now have an active website, meaning that any citizen (with access to the Internet) can now access some information about their own, or any other, local authority (Socitm, 2005). The Society of Information Technology Managers in the public sector (Socitm) has undertaken annual surveys of the progress of e-government at the local level, which provide a picture of the progress that is being made. These annual surveys evaluate websites against a range of criteria including content, accessibility and usability, and also rate the functionality of local authority websites using a four level rating scale: 'promotional', 'content', 'content plus', or 'transactional'. The categories can be summarised as follows:

Promotional sites provide basic promotional information about the organisation with very little scope for interaction.

Content sites provide useful content and encourage some interaction. They have more sophisticated promotional information (e.g. accommodation search, downloadable files) and usually include some basic user interaction (e.g. clicking on an area map to find details of local councillors).

Content plus sites provide very useful content and offer some examples of more advanced online self-service features. They allow individual users to define their own search criteria, and may include links to services such as Girobank for online payment, and online databases for items such as library catalogues, planning applications and committee minutes. Such sites also typically host information on behalf of the wider local community.

Transactional sites offer more than one type of online interaction (e.g. payment, applications, consultation, bookings) and also offer examples of customer recognition (e.g. ability to check outstanding Council Tax balance). They also provide specific e-mail contacts for different service enquiries and make widespread use of databases, downloadable forms and online form filling (e.g. for service requests and appointments).

Using this rating system, all but one of the 468 local authority websites in the UK were evaluated by Socitm in 2005 as follows:

$23(5 \%)$ local authorities had promotional sites;

$180(38 \%)$ had content sites;

226 (49\%) had content plus sites; and,

$38(8 \%)$ had transactional sites.

According to Socitm, all sites should be aspiring to offer transactional capability as soon as possible, since transactional websites enable citizens to engage fully with services. The positioning of 'transactional' sites at the pinnacle of local government service delivery reflects the aim to deliver e-government through mechanisms which are significantly interactive. The results of more recent surveys by Socitm show that, while progress is being made in achieving this goal, it is slow. By 2007, the number of transactional sites had doubled from the previous year to 121 , but this still means that only $38 \%$ of all sites offer this level of functionality. The Socitm 2007 survey also finds that uptake of online services 
by the public has increased by $27 \%$, but, while user satisfaction with council websites remains high, it is declining. Usability of the websites appears to be a key problem, despite overall improvement against many other measures (Socitm, 2007). Therefore, although it is believed that providing transactional websites is necessary and will be the key to increasing uptake and use of e-government, the evidence suggests that it is not sufficient.

\section{Technology and social inclusion}

The implementation of e-government is expected to improve access to Government services for citizens, and to improve citizen participation and social inclusion. If it is to achieve these objectives, the UK Government must ensure that those people who need these services most are able to access and use them through digital channels. Social exclusion is a multi-dimensional phenomenon (Cabinet Office, 2004) but it is widely accepted that some groups of citizens are at risk of being prevented from participating fully in society by virtue of factors such as age, disability, low income level, low educational level, cultural or language differences, and geographical or social isolation. The level of penetration of internet technologies into UK homes is around 61\% (Office for National Statistics, 2007) and is said to have reached a plateau. However groups at risk of social exclusion are least likely to have home access to the internet. Local egovernment is regarded as an integral part of the Government's 'UK Online' programme which aims to promote uptake of the Internet by citizens through making key services available online, as well as by improving access and skills. To supplement home-based internet access, therefore, the UK Government has invested in developing a range of different access mechanisms, such as public internet access points, kiosks and digital television. However, a recent report published by the Improvement and Development Agency (IECRC and Citizens Online, 2005) suggests that it is not clear whether these initiatives have helped to improve access for socially excluded groups. Evidence from a survey undertaken for the Australian government shows that e-government services are more likely to be used by those who are not at risk of social exclusion than by those who are. For example, people using the Internet to access e-government services are much more likely to be male (57\%), to live in metropolitan areas, to be under 50 years old, to be university educated and to work as professionals. Those using 'traditional' means to access government services (e.g. the telephone) are more likely to be female and to be living in households with dependent children at home (49\% compared with $43 \%$ average). Internet users living in metropolitan areas are more likely to use the Internet to contact government (57\%) than those living outside capital cities (Australian Government Information Management Office, 2005).

Disability is a significant risk factor for social inclusion and it is clearly important that e-government services meet the accessibility needs of disabled people to prevent further exclusion, as well as in terms of meeting the requirements of the Disability Discrimination Act (1995). The UK Government requires that all its local and central department websites should conform to level AA of the International World Wide Web Consortium's Web Accessibility Initiative 
guidelines for accessibility (W3 Consortium, 1999) - the lowest level being A and the highest being AAA. Again, the regular Socitm surveys suggest that progress towards this objective within the UK e-government context is slow, with only two sites having achieved level AA in 2007, and 64 having reached level A standard (Socitm, 2007).

\section{Website content}

The brief review above implies that uptake of e-government will increase as the number of transactional websites and their levels of accessibility improve. The literature on technology acceptance in fact suggests that the primary factor in driving uptake is the perceived usefulness of the system. Davis et al. (1989) assert that "Users may be willing to tolerate a difficult interface in order to access functionality that is very important, while no amount of ease of use will be able to compensate for a system that doesn't do a useful task". The surveys by Accenture and the emphasis on transactionality reflect a vision of the citizen as a customer of local government services - and indeed for many citizens in many circumstances this is the case. Yet many citizens engage with their local authorities to find information rather than (or as well as) to undertake transactions, and evidence suggests that poor information content and organisation can be significant barriers to usage of online government services. Ottens (2005), for example, states that low levels of usage "are influenced by the supply side, i.e. the information content available on public authorities' websites". Research by the Office of the e-Envoy (2003) suggests that the design of the original e-government portal (www.ukonline.gov.uk) did not direct people effectively to the areas they were interested in, but was organised according to Government's view of its operating departments. Countries with higher uptake of e-government services, e.g. Canada, tend to cluster online access around the needs of user groups or specific topics (e.g. parents, drivers, businesses), providing cross-departmental access (IECRC and Citizens Online, 2005). In focus groups conducted for the study for the Australian government a number of participants suggested poorly designed online services had prevented them using the Internet for government contacts. Most frustrating were occasions where people's queries were non-standard, and did not correspond to any of the options provided (Australian Government Information Management Office, 2005).

\section{Aim of the research}

Whilst there is clear guidance available to the developers of local authority websites about the targets that they need to meet in terms of accessibility and capability standards (e.g. from the Office of the e-Envoy, 2003), there is little available to guide the development of content in a way that meets citizens' information needs and thus to create the requisite "user pull" for the take-up of egovernment services. Such guidance would need to be derived from a thorough understanding of the information needs of citizens, gained through engagement with a diverse range of different citizens, including those with special needs and those at risk of exclusion. This would require significant effort and commitment on the part of local authorities, and a first step to achieving it would be to 
convince them of the need. The aim of the research reported here was to explore the use of scenarios as a simple tool to evaluate existing information provision on local authority websites from the perspective of different citizen needs.

\section{Methodology}

\section{Scenarios}

Scenarios have been widely used in a number of settings, often as the basis for strategic planning and decision making. However they have, in recent years, been applied in the context of information systems development as a means for enabling designers and developers to test aspects of the system under development against the needs of different kinds of users, tasks and/or contexts. Go and Carroll (2004) define a scenario as "a description that contains (1) actors, (2) background information on the actors and assumptions about their environment, (3) actors' goals or objectives, and (4) sequences of actions and events." They note that there are many different ways of applying scenarios, and point out that some applications may omit one of the elements or may implicitly express it. Scenarios based on real-life situations and users can provide developers with a powerful, simple and yet low-cost tool for evaluation.

In order to evaluate information content from a citizen perspective, a number of scenarios were generated, based on 'real-life' examples of queries for information generated within a focus group held by the researchers to explore citizens' experiences of local e-government. The scenarios chosen were:

- A young person looking for information about local skate parks;

- A disabled person looking for information about accessibility of local tourist sites;

- A single parent looking for information about local playgroups;

- An older person looking for information about help with travel i.e. 'dial-aride' type services.

These were used to interrogate a sample of local authority websites to identify the extent to which they were able to provide information to fulfil the needs of the citizens in each of the scenarios.

\section{Sample of websites}

The sample chosen for the initial evaluation were the 'top twenty' websites as ranked by Socitm in their 2005 "Better Connected" (Socitm, 2005), as shown in the list below. These websites scored highly on, amongst other criteria, the facilities offered (e.g. transactions), accessibility, and aspects of content.

1. Barking \& Dagenham, London Borough of

2. Birmingham City Council

3. Brent, London Borough of

4. Chester City Council 
5. Devon County Council

6. East Ayrshire Council

7. Exeter City Council

8. Kensington \& Chelsea, The Royal Borough of

9. Kirklees Metropolitan Council

10. Salford City Council

11. Shrewsbury \& Atcham Borough Council

12. South Tyneside Metropolitan Borough Council

13. Staffordshire Moorlands District Council

14. Stroud District Council

15. Surrey County Council

16. Surrey Heath Borough Council

17. Tameside Metropolitan Borough Council

18. Tower Hamlets, London Borough of

19. Wandsworth, London Borough of

20. West Sussex County Council

\section{Data collection procedure}

For each scenario, a number of searches were carried out, i.e.:

- search of the A-Z list - assuming the site has one;

- keyword search using appropriate terms relating to the scenario; and,

- search under any appropriate topic headings (menu) on the website related to the scenario - e.g. tourism, transport, etc.

The method was piloted using the first of the scenarios (young person). The findings of the pilot have not been incorporated in this paper because a number of the websites had changed by the time the remainder of the data had been collected.

A collaborative approach was adopted for the data collection process. Details of the proposed study were presented by Professor Frank Land and Professor Leela Damodaran on behalf of the BCS Sociotechnical group at the UKAIS (United Kingdom Academy for Information Systems) conference $22^{\text {nd }}-24^{\text {th }}$ March 2005 in Newcastle, UK, with a request for participation. A number of volunteers came forward to assist with data collection from Leeds, Plymouth, and Durham Universities (see acknowledgements for details).

\section{Analysis}

The results of the searches were collated and analysed. The result of each search was given a score of between 0 and 3 based on: 
- the ease of finding the information - for example, the number of mouse clicks, links (both internal and external) that had to be followed to find the information; and,

- the relevance/quality of the information found.

- Scores relating to the ease of finding of information were assigned as follows:

- 3 was given for finding information in 3 clicks or less;

- 2 was given for finding information using 4-7 clicks;

- 1 was given for finding information using 8 or more clicks; and,

- 0 was given for not being able to find information.

- Scores relating to the relevance of information were assigned as follows:

- 3 was given for the information being relevant and being very useful to the citizen - i.e. no further searching is required;

- 2 was given for the information being relevant and useful to the citizen may need further input, i.e. using the telephone to find more information;

- 1 was given for the information being relevant and acceptable to the citizen - information is described but is used for internal council purposes only - meeting minutes, etc.; and,

- 0 was given for no information being found.

\section{Findings}

The success rate for finding relevant information varied both according to the scenario and to the different search strategies. The findings are shown in Table 1 below.

\begin{tabular}{|l|l|l|l|l|}
\hline Scenario & $\begin{array}{l}\text { No } \\
\text { information } \\
\text { found }\end{array}$ & $\begin{array}{l}\text { Information } \\
\text { found using } \\
\text { A-Z }\end{array}$ & $\begin{array}{l}\text { Information } \\
\text { found using } \\
\text { keyword search }\end{array}$ & $\begin{array}{l}\text { Information } \\
\text { found using } \\
\text { menu search }\end{array}$ \\
\hline 1. Disabled access & $50 \%$ & $65 \%$ & $50 \%$ & $60 \%$ \\
\hline 2. Playgroups & $20 \%$ & $70 \%$ & $80 \%$ & $70 \%$ \\
\hline 3. Transport & $30 \%$ & $65 \%$ & $70 \%$ & $65 \%$ \\
\hline
\end{tabular}

\section{Table 1: Summary of findings for scenarios}

As shown in Table 1, the A-Z list was the more effective search method used. There were more scores of 3 using this method in the three scenarios: $5 \%$ in scenario $1,15 \%$ in scenario 2 , and $25 \%$ in scenario 3 . The searches also identified a range of problems in locating relevant information that we have broadly categorised as: 


\section{Too many hits}

A search on "disabled access" returned 5007 hits. This highlighted issues concerning border control for council websites where links to freely available Internet search engines provide the major search facility for the site. Citizens searching local e-government websites are in danger of being moved seamlessly via search engines to large and largely irrelevant lists of websites.

\section{Inappropriate hits}

A search on "Ring-\&-Ride" (a taxi based service for older/disabled people) produced one result that featured a local news story describing how a local boy had 'done good' and tracing his rise to becoming a world boxing champion! This highlighted issues concerning the categorisation of information and the relevance of hits.

\section{Problems with technology}

There were also significant technological problems with searches revealing (persistent) problems with software crashing and slow loading of pages, for example:

“...a link to... crashed when I tried to load it!"

And,

"...the information would have been fairly straightforward to find, had it not been for the software crash once it had loaded..."

And,

“...A-Z page took over 30 seconds to load over broadband...”

\section{Problems with navigation}

A major issue identified concerned the number of links which had to be followed to find specific information in e-government websites, for example:

"...at least 10 clicks, and therefore pages, are required to gain information..." And,

“...it is after going through a lot of trees that you stumble on disabled access information..."

The novice searcher or new user of council services online would struggle to find information. In particular, those without adequate experience within an online environment would meet with difficulty. This may indicate that such website content is not designed from an information needs perspective. Indeed, issues related to the content of local government websites were high on the list of concerns reported by the searchers.

\section{Content problems}

It was apparent that much content of local e-government websites was targeted at internal users with "results 'swamped' by minutes, policies and internal council 
documentation that were not of interest to the average citizen". From the information needs perspective of citizens this is a worrying finding, indicating a substantial gap between government vision and implementation at the local level. It is also interesting that there appeared to be very little specific information for the citizen on local e-government websites, rather content was reliant on links to external sites:

"Information disappointing, a heavy reliance on external websites with not much useful information on them"

There were also examples of good practice where some effort had been expended on engaging with the user's perspective. One small example of this was the provision of a name and email address for the council officer responsible for playgrounds so that direct contact by citizens is enabled. For the user this is an important advance on statements such as " $\mathrm{X}$ county council is responsible for the maintenance of all playgrounds within the borough" which provides little help to the enquirer seeking a local play facility.

Good practice was also in evidence when the varying search strategies employed found the same information, thus indicating that the content was adequately organised, linked and signposted. Finally, linkages to external sites providing, for example, dates of upcoming local events also indicated that some councils are being innovative in their provision of information. One caveat to this was a return visit to a local e-government website which had been noted in the early stages of

\begin{tabular}{|c|c|c|c|c|c|c|}
\hline & 1. & Surrey Heath & 1. & Devon CC & 1. & Devon CC \\
\hline & 2. & Chester City & 2. & Chester City & 2. & Chester City \\
\hline & 3. & Devon CC & 3. & Exeter City & 3. & Surrey Heath BC \\
\hline & 4. & Exeter City & 4. & Surrey Heath & 4. & Exeter City \\
\hline & 5. & East Ayrshire & 5. & Barking \& Dagenham & 5. & Barking \& Dagenham \\
\hline & 6. & Barking \& Dagenham & 6. & Salford City & 6. & Birmingham City \\
\hline & 7. & Birmingham City & 7. & Birmingham City & 7. & Kirklees MBC \\
\hline & 8. & Kirklees MBC & 8. & Kensington \& Chelsea & 8. & Kensington \& Chelsea \\
\hline & 9. & Kensington \& Chelsea & 9. & Kirklees MBC & 9. & Salford City \\
\hline & 10. & Surrey DC & 10. & Shrewsbury \& Atcham & 10. & East Ayrshire \\
\hline & 11. & Salford City & 11. & South Tyneside & 11. & Surrey DC \\
\hline & 12. & West Sussex CC & 12. & Surrey DC & 12. & South Tyneside MBC \\
\hline & 13. & Shrewsbury \& Atcham & 13. & Tower Hamlets & 13. & Shrewsbury \& Atcham \\
\hline & 14. & Tower Hamlets & 14. & East Ayrshire & 14. & Tower Hamlets \\
\hline & 15. & South Tyneside & 15. & Stroud DC & 15. & Tameside MBC \\
\hline & 16. & Stroud DC & 16. & Tameside MBC & 16. & West Sussex CC \\
\hline & 17. & Tameside MBC & 17. & West Sussex CC & 17. & Stroud DC \\
\hline & 18. & Staffordshire Moorlands DC & 18. & Staffordshire Moorlands DC & 18. & Staffordshire Moorlands D \\
\hline & 19. & Brent & 19. & Brent & 19. & Brent \\
\hline & & Wandsworth - Not classified & & Wandsworth - Not classified & & Wandsworth - Not classifie \\
\hline & & A) Ease of finding information & & Usefulness of finding information & & Collated results \& final ranki \\
\hline & & Key $-(\mathrm{CC}=$ County Coun & $=\mathrm{M}$ & [etropolitan Borough Council & D & rict Council) \\
\hline
\end{tabular}

Figure 1: Ranking of the websites in terms of ease of finding information, usefulness of the information and combined scores 
the pilot and found to be innovative and creative, which was then revisited and found to have lost many of its best features having been redesigned to meet Web Accessibility standards.

\section{Producing an overall ranking}

Lastly, the twenty websites were ranked according to the scores allocated for a) the ease of finding information and $b$ ) the usefulness of the information found. These scores were then added together (c) to produce a ranking of the highest and lowest scores amongst these 'top twenty' local authority websites. (Number $19-$ Wandsworth - is listed as 'not classified' because at the time of our evaluations their website was unavailable). The results are shown in Figure 1.

\section{Discussion}

As Table 2 below shows, this evaluation focused on an information needs perspective gives a slightly different picture of the Socitm 'top twenty' local authority websites for 2005, although with the exceptions of Surrey Heath and

\begin{tabular}{|c|c|}
\hline Ease / relevance of Information top twenty websites & Socitm 2005 Rating \\
\hline 1. Devon County Council & 5 \\
\hline 2. Chester City Council & 4 \\
\hline 3. Surrey Heath Borough Council & 16 \\
\hline 4. Exeter City Council & 7 \\
\hline 5. Barking \& Dagenham, London Borough of & 1 \\
\hline 6. Birmingham City Council & 2 \\
\hline 7. Kirklees Metropolitan Borough Council & 9 \\
\hline 8. Kensington \& Chelsea, Royal Borough of & 8 \\
\hline 9. Salford City Council & 10 \\
\hline 10. East Ayrshire Council & 6 \\
\hline 11. Surrey County Council & 15 \\
\hline 12. South Tyneside Metropolitan Borough Council & 12 \\
\hline 13. Shrewsbury \& Atcham Borough Council & 11 \\
\hline 14. Tower Hamlets, London Borough of & 18 \\
\hline 15. Tameside Metropolitan Borough Council & 17 \\
\hline 16. West Sussex County Council & 20 \\
\hline 17. Stroud District Council & 14 \\
\hline 18. Staffordshire Moorlands District Council & 13 \\
\hline 19. Brent, London Borough of & 3 \\
\hline Wandsworth, London Borough of (not classified) & 20 \\
\hline
\end{tabular}

Table 2. Ranking of the Socitm 2005 'top twenty' local authority websites for ease of finding and relevance of information 
Brent, all are in the same half of the table i.e. in the top ten or bottom ten in both evaluations.

The websites rated first and second in the Socitm survey (Barking \& Dagenham and Birmingham City respectively) are rated fifth and sixth using our evaluation based on the ease of finding information and the usefulness of the information found for citizens' information needs. Devon County Council moves from third place to first, whilst Kensington \& Chelsea and South Tyneside remain unchanged. Interestingly, Brent, rated third in the Socitm survey, is rated last when assessed in terms of meeting our sample of citizens' information needs. Surrey Heath makes the opposite transition from 16 in the Socitm survey to third in our version of the 'top twenty'.

These findings provide a snapshot of a sample of local government websites from a citizens' information needs perspective. They highlight the need to meet citizens' requirements for ease in information seeking and for relevance of the information provided. As has already been intimated above, local authority websites (like many others) are constantly changing as new information is added, as their developers strive to add new functionality such as transactional capability, and to make their sites more accessible to those with disabilities. As our results show however (Table 1), a proportion of the websites - between $20 \%$ and $50 \%$ depending on the scenario - did not return any usable information at all on the topic of interest. This leads us to conclude that a highly accessible, fully transactional website may not necessarily be a particularly useful website from the point of view of meeting a diverse range of citizens' information needs.

Such problems are, of course, not confined to local authority websites. Albers (2000), from a study of e-commerce websites, found that "the web sites contained large quantities of information. But they were arranged in a manner which didn't support the user. Rather than providing support to help the user compare models and make an informed purchase decision, they simply dumped a collection of facts or technical specifications. The user had to sort out the facts and make decisions about how to compare the models. The result was frustrated and alienated users who were unable to use the web site to make a decision."

Furthermore, while the topics of the searches were drawn from 'real life', the searches were conducted by academic researchers who are very familiar with the internet and with search strategies. 'Real' users will not necessarily have such skills. As Bates (2002, 9 -13) points out, "people are generally quite unaware of their usual information seeking behaviours, they do not even have as a part of their conscious thought the idea that one needs searching skills and search planning - let alone know of specific strategies that they can follow to find what they want." In the information rich world in which we live, Bates notes (2002, 613), people not only have to search actively for information, but "also have to master a fair amount of ancillary skills and knowledge just to be able to search for the information, with no guarantee that effort will actually lead to an answer."

Not only must web designers provide appropriate information, but they must take into account (in the way that they organise it) the way(s) in which users are likely to search for it. As local authority websites become increasingly sophisticated, 
they contain greater quantities of information, increasing options for action, and more and more links to other sites. Humans cannot efficiently process large amounts of information unless it is properly organized (Woods and Roth, 1988). It must be arranged and presented in a manner which supports the users' goals and information needs. Even with high information content, poor design will mean that the information becomes both hard to find and hard to process (Bowie, 1996). Waern claims that one reason why information systems fail "lies in the differences in perspective between the data generators and the information searchers" (Waern, 1989, 172). Professional decision makers (the data generators) expect to have to draw inferences from complex data, whereas citizens seeking straightforward answers to straightforward queries of the type used for our research will potentially not have the skills, and almost certainly will not have the motivation or patience, to adopt this strategy. As a result, a web-based information system which is designed to meet the typical information behaviour of web-literate professional decision makers is not likely to meet users' real world needs.

\section{Conclusions}

The research reported above suggests that a scenario-based approach to evaluating information content can provide a different and useful perspective when assessing local authority websites, which might help local authorities to identify the extent to which the information they provide might meet citizens' information needs. However, to be effective, scenarios must be based around real information needs, and therefore cannot be a substitute for engaging with citizens.

While local authorities have been consulted by Government about the development of e-government strategies and systems, there is little evidence of systematic or widespread participation of other stakeholders, particularly citizens. This demonstrates a gap between Government aspirations for improving participation and social inclusion, and the activities which are actually taking place. There appears to be far more emphasis on technological aspects of delivery than on engaging citizens in identifying real needs and participating in decisionmaking regarding perceived priorities and methods of service delivery (Damodaran et al., 2005). A concerning consequence is that levels of understanding of user requirements are therefore insufficient to inform effective service design and delivery, giving little impetus for improved uptake by citizens.

It is now widely recognised that effective information systems need to be based firmly on the requirements of their users and stakeholders, e.g. as instantiated by the International Standard ISO 13407, Human-Centred Design, 1999 (ISO, 1999). Indeed there are numerous well-documented examples of public systems in the UK which have failed precisely because they have not followed this principle (e.g. Finkelstein and Dowell, 1996; National Audit Office, 1999). Citizens are key stakeholders in systems for e-government, but they appear as yet to be having little input into their creation and development. 


\section{References}

Accenture (2003) e-Government leadership: engaging the customer. URL: http://www.accenture.com/Global/Services/By Industry/Government and Public Service/R and I/CitizensView.htm [accessed 27.9.07].

Accenture (2004) e-Government report: high performance, maximum value. URL: http://www.accenture.com/Global/Research and Insights/By Industry/Governme nt and Public_Service/HighValue.htm [accessed 27.9.07].

Accenture (2005) Leadership in customer service: new expectations, new experiences. URL:

http://www.accenture.com/global/research_and_insights/by_industry/government and public_service/leadershipexperiences.htm [accessed 26.9.07].

Accenture (2006) Leadership in customer service: building the trust. URL: http://www.accenture.com/xdoc/ca/locations/canada/acn_2006_govt_report_FIN AL_sm.pdf [accessed 26.9.07].

Albers, M. (2000) Information design for websites which support complex decision making. In: Proceedings of 47th annual conference of the Society for Technical Communication. Washington: STC.

Australian Government Information Management Office (2005) Australians' use of and satisfaction with e-government services. URL:

http://www.agimo.gov.au/publications/2005/june/e-government_services [accessed 26.9.07].

Bates, M. J. (2002) Toward an integrated model of information seeking and searching. Keynote address, $4^{\text {th }}$ international conference on information needs, seeking and use in different contexts, Sept 11-13 2002, Lisbon, Portugal. URL: http://www.gseis.ucla.edu/faculty/bates/articles/info_SeekSearch-i-030329.html [accessed 26.9.07].

Bowie, J. (1996) Information engineering: communicating with technology. Intercom 43(5), 6-9.

Cabinet Office (2004) Enabling a digitally United Kingdom: a framework for action. London: Cabinet Office. URL:

http://www.cabinetoffice.gov.uk/publications/reports/digital/digitalframe.pdf [accessed 26.9.07].

Damodaran, L. Nicholls, J., Henney, A., Land, F. and Farbey, B. 2005. The contribution of sociotechnical systems thinking to the effective adoption of eGovernment and the enhancement of democracy. Electronic Journal of eGovernment [online], 3(1). URL: http://www.ejeg.com/volume-3/vol3-iss1/vol3iss1-papers.htm [accessed 26.9.07]

Davis, F.D., Bagozzi, R.P. and Warshaw, P. R. (1998) User acceptance of computer technology: a comparison of two theoretical models. Management Science, 35(8), 982-1003.

Disability Discrimination Act (1995) London: TSO. URL: http://www.opsi.gov.uk/acts/acts1995/1995050.htm [accessed 26.9.07]. 
Finkelstein, A and Dowell, J. (1996) A comedy of errors: the London Ambulance Service case study. In: Proceedings 8th International workshop on software specification and design IWSSD-8. Washington DC: IEEE CS Press.

Go, K. and Carroll, J. (2004) The blind men and the elephant: views of scenariobased system design. Interactions, 11(6) 44-53.

IECRC and Citizens Online (eds.) (2005) eGovernment: reaching socially excluded groups? Improvement and Development Agency (IDeA). URL: http://www.idea.gov.uk/idk/aio/1075006 [accessed 26.9.07].

International Standards Organisation (1999) Human-centred design processes for interactive systems. ISO 13407. Geneva: ISO.

National Audit Office (1999) The passport delays of Summer 1999. HC 812 Session. URL: http://www.nao.org.uk/publications/nao_reports/9899812.pdf [accessed 26.9.07].

Office of the Deputy Prime Minister (ODPM) (2004) Defining e-government priorities and services and transformations outcomes in 2005 for local authorities in England. URL: http://www.purbeck.gov.uk/docgallery/1142.pdf [accessed 27.9.07].

Office of the e-Envoy (2003) Quality framework for UK Government website design: usability issues for government websites. London: Cabinet Office. URL: http://archive.cabinetoffice.gov.uk/egovernment/docs/qualityframework/pdf/quality.pdf [accessed 26.9.07].

Office for National Statistics (2007) Household internet access data. URL: http://www.statistics.gov.uk/cci/nugget.asp?id=8 [accessed 30.8.07].

Ottens, M. (2005) Internet usage by individuals and enterprises. Luxembourg: Eurostat.

Society of Information Technology Management (Socitm) (2005) Better connected 2005. Northampton: Socitm. URL:

http://download.edinburgh.gov.uk/stats/Betterconnected2005final.pdf [accessed 27.9.07]

Society of Information Technology Management (Socitm) (2007) Better connected 2007. Northampton: Socitm.

Waern, Y. (1989) Cognitive aspects of computer supported tasks. New York: Wiley.

Woods, D. and Roth E. (1988) Cognitive engineering: human problem solving with tools. Human Factors 30(4), 415-430.

World Wide Web Consortium (W3C) Web Accessibility Initiative (1999) Web Content Accessibility Guidelines 1.0. URL: http:/www.w3.org/TR/WCAG10/ [accessed 26.9.07]. 


\section{Acknowledgement}

The authors would like to thank their colleagues in the BCS e-democracy study group for their assistance with this study. Special thanks are due to Colin Ashurst (Durham University), Andy Phippen (Plymouth University), Prince Magagula and Owen Johnson (Leeds University), and Mark Shelbourn and Joan Stenson (Loughborough University) for their contributions to the data collection and analysis process. We also thank UKAIS for the opportunity to present our research and invite collaboration at its Newcastle conference in 2005. 